\title{
Exploring design among small hospitality and tourism operations
}

Received (in revised form): 12 September 2008

\begin{abstract}
Abel D. Alonso
is Assistant Professor at Auburn University, USA. His research interests include business-related areas of concern of small and medium enterprises (SMEs), urban (eg hospitality) and rural (eg wineries), as well as wine consumer and winery visitor behaviour.
\end{abstract}

\section{Alfred Ogle}

is a lecturer in Hospitality Management at Edith Cowan University, Western Australia. His research interests include hotel guest-management interface, hotel product and service innovation, and HRD and training in the hospitality industry.

\begin{abstract}
Despite numerous efforts by researchers to examine the importance of design among hospitality and tourism operations, little if any attention has been paid to small operations of these industries, for example, to the level of importance operators place on facility design. Semi-structured face-to-face and phone interviews among 30 businesses located in Western Australia were used in the data collection process. Overall, respondents not only indicated being actively involved in the design of their small businesses, but also emphasised the importance of maintaining a balance between the physical aspect and their operations' natural surroundings. Simplicity and efficiency are also identified and used as operations' appealing factors. Because of the important role that small enterprises play in the hospitality and tourism industries, the findings of this study have important implications for ways in which design is being utilised among these operations to promote efficiency, comfort and value to guests' experience. These areas, in turn, could positively contribute to businesses' well-being. This exploratory study investigates an area that to date, despite its fundamental importance, has received limited attention in different fronts, including in academic research.
\end{abstract}

\section{Keywords:}

design, small hospitality and tourism operations, Western Australia, operators' views

Abel D. Alonso

Hotel and Restaurant Management 328B Spidle Hall

Auburn University

Auburn

AL 36849,

USA

Tel: +13348443291

Fax: +13348443279
Journal of Retail and Leisure Property (2008) 7, 325-337.

doi:10.1057/rlp.2008.23; published online 15 October 2008

\section{INTRODUCTION}

Design in hospitality and tourism facilities is regarded as a core aspect that can contribute towards adding value to both operations and guests 
(Stipanuk, 2006). Design, according to Buchanan (2001), 'is the human power of conceiving, planning, and making products that serve human beings in the accomplishment of their individual and collective purposes' (p. 9). Such a definition not only suggests that design is inherent in all aspects of human endeavour, but also relates fundamentally to people, thereby highlighting the criticality of design to hospitality and tourism industries. The design of a hospitality/tourism establishment can provide an identity or character to the business and project the operation's appeal and vision to visitors, or potential visitors. These elements, both the tangibles such as architecture, décor and furnishings (Nobles, 1999) and intangibles such as ambience, are also contributors to guests' overall experience at a destination, and can be decisive factors in determining guests' satisfaction or dissatisfaction during their stay. Resulting potential business implications can be in the form of repeat visits or word-of-mouth advertising.

Despite a significant volume of studies focussing on hospitality operations' design, various aspects of this dimension have received limited attention in contemporary research. Johns (1993), for instance, notes the lack of literature 'dealing with the relationship between design, construction and the efficient operation of hotel assets' (p. 20). Heide et al. (2007) assert that 'there is an apparent lack of empirical research that addresses ambience and its role in hospitality settings' (p. 1315), and Bitner (1992) identifies the 'lack of empirical research or theoretically based frameworks addressing the role of physical surroundings in consumption settings' (p. 57). According to Zemke and Shoemaker (2007), studies on the physical elements of retail and consumer product marketing eclipse those conducted in the area of services marketing, reflecting hoteliers' perception that they have little control over the interior aesthetics of their properties (Losekoot et al., 2001).

In addition, to date, contemporary research has dealt very little with the design dimension and its importance among small-size hospitality and tourism operations, including knowledge that might answer the following questions:

- To what extent are operators using design as a competitive advantage?

- To what extent do operators use design to achieve efficiency, while attracting visitors/guests in the process?

As a result of lack of research in these dimensions, very little is known about the relationships between small operators and their business's design in these and other areas of their operations. This study seeks to examine these relationships from operators' points of views.

\section{LITERATURE REVIEW: DESIGN IN TOURISM AND HOSPITALITY OPERATIONS}

Several definitions seek to explain the meaning of design, with one of them suggesting that design entails decorations, shapes, sizes and styles, all aspects that can impact 'soft' factors such as a building's ambience, comfort, image and style, and 'hard' factors such as cost, ergonomics, 
noise, safety or space allocation (Katsigris and Thomas, 1999, in Ransley and Ingram, 2001). An extensive body of literature on design has emerged over the years, including in the hospitality and tourism industries, underlining the significance of the design dimension for both operations and customers. For hotels, for example, design is a significant tool in enhancing the building's attractive appeal, creating an atmosphere in public areas, such as lobbies, and attracting visitors in the process (Ransley and Ingram, 2001, p. 79).

Countryman (2001) asserts that a hotel's physical design modifies guests' inferences and perceptions of quality. In fact, research has also examined the importance of design in front-line areas of hospitality operations, with Withiam (1989) and Countryman and Jang (2006) discussing the critical importance of lobby design for hotels, and Thapa (2007) investigating how design features of hotel lobbies can have an impact on customers and their behaviour toward the hotel's overall environment. These studies demonstrate that the design element constitutes a critical aspect in adding value to hotels, with potential business implications in the form of positive word of mouth and future increased business. Hotel design can also contribute to creating tangible attributes that visitors can identify (West and Hughes, 1991, p. 364), and at the same time can provide quality, including aesthetic quality, to enrich guests' experience (Johns, 1993, p. 23).

The creation of attractive environments through design can support operations in their quest for providing ambience and environment (Kotler, 1973). Moreover, the use of functional and aesthetic elements such as a building's architecture, style and layout is critical (Heide et al., 2007). Apart from providing for the welfare of consumers (Baker et al., 2002), building design can also serve as a channel in facilitating teamwork, communication and business' creativity (Earle, 2003). Ambient conditions, space/function and signs, and symbols and artefacts are critical aspects that enrich the businesses' interior environment (Bitner, 1992; Brady and Cronin, 2001), and can be factors that help organisations to improve their corporate identity (West and Purvis, 1992).

Research has also identified more basic and practical areas related to the design dimension, including usability aspects (Alexander, 2006) and those related to the functionality of a building (Steiner, 2005). For instance, some studies explain that hospitality operators also need to pay attention to a hotel's spatial relationships, ensuring that hotel space is used efficiently (Anonymous, 1993). Hekkert (2006) notes that 'a visual pattern is pleasing to the eye when relatively simple design features reveal a wealth of information' (p. 7), emphasising the relevance of simple but succinct messages communicated in a positive manner to guests. At the other end of the spectrum, poor design is a cause of major problems in hotels (Jones, 1999). Hence, because consumers pay attention to physical and tangible elements (Nickson et al., 2002), including a hotel's interior design (Bowie and Buttle, 2004), managers should think of design in very serious ways and have it high in their strategic agenda despite the prevailing view that a property's physical infrastructure development is 'costly and subordinate to other strategies' (Losekoot et al., 2001, p. 297). 
Siguaw and Enz (1999) explain that 'One attribute that travellers often seek in a hotel is its ability to make the traveller feel comfortable while on a trip. Increasingly, hotels are using residential or home-like style and design to accomplish that task' (p. 44). Design can also play a critical role in smaller hospitality operations, however. For example, studies conducted among bed and breakfast operations (B\&Bs) highlight the usefulness of design, particularly because word of mouth is the strongest marketing tool for B\&Bs (Withiam, 1997, p. 13). Thus, facility design in hospitality and tourism operations and management's involvement all go hand in hand towards the achievement of a common goal: enhancing customers' experience, regardless of the type of hospitality operation, that is, whether it is a hotel or a B\&B facility.

According to Stipanuk (2006), 'a facility's design will clearly dictate the scope of the facility management function' (p. 14), with management focussing on facility layout, materials, quality, types of construction and systems. Siguaw and Enz (1999) go a step further, using the term 'champions' to define operators with pioneering, practical and creative thinking who use design as a practical yet critical business tool:

...champions recognise that the design of a hotel and the guest room itself is a crucial element in the guest's travel experience. Therefore, the hotel and guest room must become part of the total entertainment and sensory package that the guest is seeking (p. 49).

Other studies focussing on hotel design also indicate that while providing a pleasurable experience to guests is paramount, addressing environmental concerns can be equally important. In the case of the Orchid Hotel in Mumbai, India, Jones (2002) presents an overview of ways in which this establishment combines design and comfort with environmentally responsible strategies that include energy-saving systems, minimisation of pollution and water usage, and waste reduction. Ayala (1995) also highlights environmental awareness, discussing the potential for the hospitality industry in Fiji to set a precedent as a successful ecotourism destination, that is, extending from a current 'megatrend' that might contribute to the merging of international tourism and international ecotourism (p. 39). In this particular scenario, accommodation facilities' design could play a vital part in preparing businesses to fulfil their newly assigned environmentally friendly roles. In 1987, Lawson indicated that holiday resorts would face more stringent planning restrictions in years to come, including their design, to comply with environmental regulations (p. 143), a phenomenon that has increasingly gained in significance and popularity in recent years.

Overall, combining design, comfort and efficiency seems to be a challenging yet rewarding strategy for hospitality operations to integrate to contemporary business practices. This study investigates to what extent small hospitality/tourism operators' are implementing this strategy.

\section{METHODOLOGY}

During January 2008, a total of 51 small tourism and hospitality businesses were approached by mail. These operations comprised 37 
$\mathrm{B} \& \mathrm{Bs}$ located in and around the city of Perth, including the rural areas of the Chittering Valley, Bindoon and Gingin, some 45 minutes drive from Perth's central business district (CBD). In addition, 14 small tourism and hospitality firms open to the public and comprising animal parks, breweries, theme restaurants, galleries and food factories located in the Swan Valley region (some $20 \mathrm{~km}$ inland from Perth's CBD) were contacted. Because of its proximity to Perth, in recent decades the Swan Valley region has become a very popular tourist destination, featuring numerous leisure activities, traditionally wineries, but more recently a wide range of tourist attractions.

Convenience in the form of geographical proximity to the researchers' university, and the knowledge and familiarity of the researchers with these areas were fundamental reasons for choosing this sample of businesses. The objective of exploring operations in subrural and rural areas around Perth, an area where limited research has been conducted to date, was an additional reason for choosing the location and type of businesses. The time of the year, the summer season in Western Australia, coincided with the post-Christmas holiday period, a time that was believed to be less demanding for potential respondents to participate in the study.

A letter explaining the purpose of the study, which at the same time served as a formal invitation to participate in the study, was sent to all the 51 businesses. In the two weeks following the first mail contact, a followup procedure took place via phone calls to secure businesses'

participation. In all, the breakdown of businesses accepting the invitation to participate in the study was as follows: $21 \mathrm{~B} \& \mathrm{~B}$ operations, and nine small tourism and hospitality businesses. Overall, 30 operators accepted the invitation to participate, representing a response rate of 58.8 per cent. The semi-structured interviews were conducted face-to-face and over the telephone, and took between 5 and 30 minutes to complete.

\section{FINDINGS: THE IMPORTANCE OF BUILDINGS' CHARACTER AND EFFICIENCY}

Much of the information gathered from respondents identifies a clear awareness about the preservation of the building's character, as well as efficiency issues, and how the design of the operations comes into play with these dynamics. For instance, feedback from an operator of a local Australian aboriginal museum not only identifies the importance of emphasising the cultural aspects and theme of the business, but also identifies environmentally friendly details: 'we are an aboriginal run and operated enterprise and rightly or wrongly people feel that aboriginal people should be very connected to nature and to the land and that is our spiritual tradition. So they really like to come here and see what we have done with a modern building in terms of making it more environmentally friendly. People love the open rafters for example; that feeling of light and space and airiness. You can imagine if you put a fixed ceiling in here; it would look like a white box. We wanted to create something that is much lighter and airier and have that access to the rural environment outside because you have got all those beautiful trees outside and 
wherever you look in the gallery you can see you are surrounded by nature and I think that really works well for us and for the customers. That is what we wanted, that is what we are passionate about and I think that flows over into our relationship with our customers as well'. Thus, not only are visitors' perceptions critical to this operator, but also the promotion of culture in as many aspects of the operation as possible, thereby engendering a connection with visitors. The operator's views on providing the appropriate atmosphere that mirror the theme of the business further emphasise the importance of this dimension, as illustrated in some studies (see, eg, Ransley and Ingram, 2001).

The manager of a winery emphasised the relevance of rustic and casual styles, while at the same time maintaining a balance of simplicity, nonextravagance and unpretentiousness in the design: 'The design is very important because as a cellar door you need to be as welcoming as possible. The thing about this cellar door in particular is that it is not as professionally done as at other wineries but I think that is what people like about it. It has got character and certainly it has floors but people appreciate that because people that come here they want to go to a cellar door ... You just want the winery to be nice; you just do not want to do too much with it; you just want to be quite subtle to everybody's taste, so you do not want to go over the top. With this place it is nice because a lot of the artwork we have on the walls we get locally and so people really do experience the Swan Valley in that sense, also in that all the artwork is local'. These comments are in accord with Hekkert's (2006) view of emphasis of simplicity in the building design. The manager's additional comments also illustrate how design can transcend beyond the winery visit to aspects that include the presentation of the wine: 'It is a similar story with having the right label on a bottle of wine; people say that of course labels do not matter but of course they do matter a lot'. This design simplicity does not translate into austereness, plainness or even minimalism; it does, however, suggest the subtle manner in which the design harmonises with the local setting and function, which is highly site/location dependant, as illustrated in the following section.

\section{RESPONDENTS' OWN CONTRIBUTION TO THEIR OPERATIONS' DESIGN}

When having the opportunity to make alterations in the surroundings or the physical aspects of the buildings, other operators were able to unleash their creativity and design vision to blend it into their business strategy. This is, for instance, the case of a reptile farm operator: 'To a certain extent we have designed this place this [rugged] way on purpose. Lots of things have been economics of what you do. We designed something that can be changed easily and that has an outback look. Customers make comments; they like the [Australian] bush, especially in the back where we have a little picnic area. They like the trees and some of that was designed by accident because we had a nursery and some of the plants "escaped" from their pops, so we got these huge gum trees. It worked really well and people love it; they love the bush and we have kept it as it is. This structure here is really a family shed built some 60 years ago; it 
was built far away. It was moved over here, laid on the ground for 13 years and we reconstructed it. It used to be a wood shed; so there is actually a history behind this shed; that is why this has been put here as our entrance because it does have a family history and people do remember it if they ever saw it before'. Clearly, this creative approach might pay dividends to the operators, who might benefit from a rugged, countryside appearance, a set of critical components for outsiders travelling to Perth and eager to see at least some glimpses of the Australian outback or rural image.

Among other operators who mentioned being very involved in the design process of their businesses, one in particular emphasised the importance of purposely adopting the area's characteristics and surroundings as a means to attract overseas customers: 'Our bed and breakfast was purpose built. Our main market would be Southeast Asia and we designed our programme around short stays, people who are on short holidays and wanting to have an Australian country farm experience'. These comments are in line with Carmichael (2005), who highlights the aesthetic value of the rustic and rural appeal, including buildings with an old farm appearance, elements that help connect with visitors and contribute to a more pleasurable experience. The comments also demonstrate how design can be manipulated to suit a particular customer segment, further emphasising the strategic importance of the design element.

In several cases, operators were not able to be involved in the design process. For instance, for the operator of animal reserve who was renting this operation, not being allowed to provide his own input in the operation's design was very frustrating, particularly because he was clearly disenchanted with the current design of the business: 'It is terribly badly designed, but we did not design it. We can only utilize and use what we have got. I would change the whole building if I could and do things a lot different, but the simple idea was to have a one way system, but we are thinking of changing the outside and making into something I call "common land." From the customer point of view I think it is not a problem but it is our problem; it is hard to work'. Despite this very dissatisfying situation, the operator appeared to be willing to compromise with current design-related issues: 'Security is also a reason to have a one system because that way people are not against each other; but again, many shops in Perth would like to have our souvenir turnover'. Thus, in this case, it is apparent that financial rewards offset inconveniences.

An animal park operation faced similar challenges of starting a business in an already built and designed facility: 'From a building point of view, this [building] was not built for this operation; it was built for another operation and it has been added to ... I would like to have more funding to add to it'. Having purchased the land and buildings, this operator was looking at environmentally friendly ways to cope with the weather in different seasons. If I had the funds to do it, I would probably have sealings to it to make the air-conditioning more effective in the summer months; same in the winter with the heating. I would also have more buildings for people to sit in on rainy days; more shelter for the hot 
days. We planted 85 trees last summer but they take a long time to grow; so fortunately we got a few olds [trees] around but nowhere near enough'.

The dilemma of some operations moving into an existing building as tenants also applies to the management of a brewery that is open to the public and offers restaurant facilities: 'We are not really gripped with the way this building presents. It is OK and it has got a good feel, particularly in the outside areas, but we are very dissatisfied with the inside presentation... The inside presents like a dining hall rather than a brewery, so it just reminds people of eating at school hall. So we are looking at doing something at the inside for sure. The outside is not so bad; the outside has a lot of feel to it and we get a lot of positive feedback of the outside; but it is high on the list of things to rectify in this area'. Thus, this operator acknowledges the importance of design as going hand in hand with the provision of a brewery experience, and sees the urgency to rectify existing flaws in the interior design as a crucial component to attract customers.

A nougat factory manager also shared similar experiences with the operation's existing design: 'We did not build the building, so in many ways we were stuck with the existing design. But the previous business did not have a good reputation so for us the need to make a very, very strong positive impact, as soon as someone walked in, and even before people walked in was very important because we not only had to create a good reputation for ourselves but also shake off the reputation of the previous business'. In this particular case, once again the importance of design as a critical business strategy came into play: 'We did a lot of things, like we redesigned all the outdoor area, put in [an] al fresco section, did the gardens from the outside. At the moment it looks pretty bare but we planted lawn and it will take 12-18 months to grow. As soon as it grows it will add a lot of value and a lot of appeal. On the interior we have redone the bathrooms, brand new ceilings; we put timber ceilings in the whole retail area... just a lot of details putting all places'. The importance of customer feedback for this operator is also well reflected in the following comments: 'All this has had a huge impact. A lot of people when they walk in comment that the place is really nice and I think it helps us when you are turning around having a premium product, you need something to display your product and are pretty confident that if we had left the building the way it was we would not have been able to make the same impact and the reputation that we have'.

Some owners of the participating B\&Bs also acknowledged the repercussions of their direct input in their property's design: 'If we did it again we would improve. When we started what we found is we were not that good [yet in the business] and we used what they call the KISS principle: keep it simple stupid. Our original intention was to build the rooms separate, but after talking to someone who had been in the business for a long time he told us "No, no, go straight for this." It is just as effective and costs less'. These owners discovered over time that the simple design had in actuality become a liability.

Function and form are closely interrelated, as demonstrated in another respondent's concept: 'We have only been in operation for 15 months. The guests have their privacy and I have my privacy; that is the way we 
designed it'. Privacy was paramount for another operator when designing the B\&B operation: 'it has to be attractive to present to people because this is a very small $\mathrm{B} \& \mathrm{~B}$, but also the internal layout is extremely important, that we can separate our half of the property off from the guests' house. Everyone has their own privacy and their own space. We receive lots of positive feedback from guests; they really feel that it is an excellent setup that we have'.

\section{THE IMPORTANCE OF OPERATIONS' PHYSICAL SURROUNDINGS}

The surroundings can be a critical attraction point for many customers, in some cases comparable to the relevance of the building's exterior or interior design, as the following restaurant owner's comment indicates: 'It [physical design] is very important because it probably attracts more people; people are looking for different things. Sometimes people's eyes can "buy" a lot. Somebody told me that in some restaurant people did not matter about the food; it was the setting that was important...' These comments also identify the operator's awareness of the facility's potential and the value of its appeal to visitors.

Similarly, for some B\&B owners the surroundings also play a critical role in welcoming visitors: 'I think it is very important to have a nice looking [place] if they [guests] want to come. This is a little cottage and ... I like to keep the garden pretty and I really like to keep the cottage shiny and clean'. Another respondent went even further in her comments, identifying a basket of fundamental elements that are encapsulated in the facility design dimension: 'There are different elements and they are very important. The fact that the property is one hour from Perth and people find that very convenient ... The layout of the house is very important and the house is a beautiful design. All the rooms are large and spacious, so this gives a lovely feeling of freedom. The design also incorporates glass sliding doors, very large glass sliding doors that act as windows so when people are there in the home, from every room they have a view out to the exterior. On one side they look over the valley; the other side they are looking at an orchard. And as far as the decoration it is plain and it is minimalist and it has got a lot of character and we like to have art from the local area represented in the home and we have got historic pieces from the area in the home... So the people when they arrive they feel welcome'. These proactive views clearly indicate a clear intention to involve local producers and collaborate with them to enhance guests' stay, and potentially build long-term relationships and word of mouth.

\section{CUSTOMER FEEDBACK ON OPERATIONS' DESIGN}

Guests' comments can also reflect on the importance of design, and at the same time provide operators with valuable information: 'We get feedback about people commenting how much they like the house and the high ceilings, the decorative plasterwork. The design of the building ... well, we thought that the design of the building actually suited doing a bed and 
breakfast because we can totally shut the front section of the house and the back section so we have privacy and so do they. In our visitors' book we got really good feedback'. These comments are echoed by those of an ice-cream factory manager: 'We have a lot of positive feedback. The cream colour in which the interior is painted gives the place a light effect. Obviously the outside area as well where people sit in, surrounded by the bush. So we get wildlife come in here as well; lizards, birds, etc. The building is far from the road; it fits with the environment, and people can comfortably sit in here near the trees'.

In some cases, the perception of the real size of the operation might have an impact in case guests are looking for a cosy environment. Moreover, guest-friendly facilities, even details that may have little apparent value, can make a difference between a guest choosing to stay at a particular accommodation facility, as the following B\&B operator commented: 'to give you an example, one couple that has just booked in, one of the reasons why they came up here is because it has no steps in the entire property. So the building has been made so that all the rooms sit side by side; there are no steps. The lounge and dining areas are incorporated into the main building so that [customers] do not have to walk very far to get their meals from their sleeping areas, from the entertainment area. So, the interior and exterior designs are very important to us'. This emphasis on the operation's physical characteristics echoes that found in contemporary research. For example, in their study of hotel design, Rutes et al. (2001) explain that

\section{A relatively less efficient (and, thus, more expensive) plan type may offer more variety in room types than an efficient construction design, as well as afford a more interesting spatial sequence, shorter walking distances, and other advantages that affect the guest's perception of the value of the hotel experience (p. 78).}

Finally, while overall establishing a small hospitality or tourism operation can be a very daunting task, this challenge can be further exacerbated when the entire design process has to be redeveloped from its initial stages: 'When I bought the place it was a disaster; it was on the market for 14 months and no one would touch it because it was such a disaster. It was too much work and most people do not want to work these days. It [the operation] did not have a flower, a frog, a bird, a tree, a rose or anything... the grass was all dead; it was all brown and dry because it was closed for so long, but it was never nice in the first place. It did not have a nice energy, you know?' Despite the difficulties involved in marketing a rural hospitality operation in an area distant from main tourist traffic, the same operator sees progress and rewards after all the investment made on the property: '... I have been working so hard. I sold my house so I could invest the money in it because I am in the middle of nowhere so business is not booming of course ... I receive good feedback from people all the time. I have put silk underneath the al fresco dining and everyone says it looks wonderful for weddings, receptions and things like that, and that it is so much nicer and everyone comments on the restaurant'. 


\section{CONCLUSIONS}

While much has been explored in regard to buildings' design, including hospitality facilities' design, to date little has been reported among small hospitality and tourism operators. This study investigated these dimensions from a group of 30 small operators located in the outskirts and rural areas outside the city of Perth. Operators' comments indicate their awareness of and the value they place on their businesses' design. Moreover, operators' comments indicate their commitment to using design as a strategy to 'sell' their business concept to visitors in several forms. For example, some operators aim to preserve the establishment's character, blending the physical components of the building with the natural surroundings, and in some cases even manipulating the operation so that it follows environmentally sound practices. All these strategies might have a number of business implications including the potential impact of visitors' perceptions of the operations that might directly or indirectly contribute towards businesses' bottom line in the form of repeat visits or word-of-mouth advertising.

While the general consensus among respondents points to positive feedback visitors/guests provide, future studies could further investigate the visitor/customer dimension to provide a clearer picture of the extent to which design may impact guests' choice when selecting a particular operation. Future studies could also examine guests' or visitors' most valued areas of small operations' design, particularly regarding new trends of more innovative design, environmental soundness or even operations' design involving their surroundings. Furthermore, studies could explore information to answer the following questions:

- To what extent do visitors prefer the more 'natural' or rustic design of the operation?

- To what extent would visitors sacrifice comfort in exchange for experiencing the area's true and natural background?

- To what extent do visitors look for more sophistication despite the characteristics of the area, namely a rural area, where the operation is located?

— To what extent do visitors' value the operations' efforts to follow environmentally sound procedures?

These areas could provide operations with valuable information about their customer base, allow them to put long-term strategies in place to fulfil visitors' demands, and to potentially benefit in the process in the form of enhanced commercial opportunities. Clearly, design may provide many advantages to both the operation and visitors, and its significance transcends simple aesthetic principles. As many of the comments in this study suggest, hospitality and tourism operations need to pay attention to many aspects of their design. The competitive nature of the hospitality and tourism industries is also adding more complexity, and business will have to continue providing a pleasurable environment to their guests. In return, it is critical that guests provide much needed feedback to operators and that operators are receptive and accept such feedback as a way to increase their level of competitiveness. 


\section{References}

Alexander, K. (2006). The application of usability concepts in the built environment. Journal of Facilities Management. 4(4), 262-270.

Anonymous (1993). Spatial planning for hotel design. International Journal of Contemporary Hospitality Management. 5(2), 10-12.

Ayala, H. (1995). From quality product to eco-product: Will Fiji set a precedent? Tourism Management. 16(1), 39-47.

Baker, J., Parasuraman, A., Grewal, D. \& Voss, G.B. (2002). The influence of multiple store environment cues on perceived merchandise value and patronage intentions. Journal of Marketing. 66(2), 120-141.

Bitner, M.J. (1992). Servicescapes: The impact of physical surroundings on customers and employees. Journal of Marketing. 56(2), 57-71.

Bowie, D. \& Buttle, F. (2004). Hospitality Marketing: An Introduction, Elsevier Butterworth Heinemann, Burlington, MA, USA.

Brady, M.K. \& Cronin, J.J. (2001). Some new thoughts on conceptualizing perceived service quality: A hierarchical approach. Journal of Marketing. 65(3), 34-49.

Buchanan, R. (2001). Design research and the new learning. Design Issues. 17(4), 3-23.

Carmichael, B.A. (2005). Understanding the wine tourism experience for winery visitors in the Niagara region, Ontario, Canada. Tourism Geographies. 7(2), 185-204.

Countryman, C.C. (2001). An atmospheric scale for the evaluation of hotel lobbies, Unpublised doctoral dissertation, Purdue University, Purdue, Indiana.

Countryman, C.C. \& Jang, S. (2006). The effects of atmospheric elements on customer impression: The case of hotel lobbies. International Journal of Contemporary Hospitality Management. 18(7), 534-545.

Earle, H.A. (2003). Building a workplace of choice: Using the work environment to attract and retain top talent. Journal of Facilities Management. 2(3), 244-257.

Heide, M., Lærdal, K. \& Grøhaug, K. (2007). The design and management of ambience Implications for hotel architecture and service. Tourism Management. 28, 1315-1325.

Hekkert, P. (2006). Design aesthetics: Principles of pleasure in product design. Psychology Science. 48(2), 157-172.

Johns, N. (1993). Productivity Management through design and operation: A case study. International Journal of Contemporary Hospitality Management. 5(2), 20-24.

Jones, P. (1999). Operational issues and trends in the hospitality industry. Hospitality Management. $18,427-442$.

Jones, P. (2002). The Orchid hotel. Tourism and Hospitality Research. 3(3), 277-280.

Katsigris, C. \& Thomas, C. (1999). Design and Equipment for Restaurants and Foodservice, John Wiley and Sons, New York.

Kotler, P. (1973). Atmospherics as a marketing tool. Journal of Retailing. 49(4), 48-64.

Lawson, F. (1987). Physical aspects. Tourism Management. 8(2), 143-146.

Losekoot, E., van Wezel, R. \& Wood, R.C. (2001). Conceptualising and operationalising the research interface between facilities management and hospitality management. Facilities. 19(7-8), 296-303.

Nickson, D., Baum, T., Losekoot, E., Morrison, A. \& Frochot, I. (2002). Skills, organizational performance and economic activity in the hospitality industry: A literature review, Research Monograph No. 5, SKOPE, Universities of Oxford and Warwick.

Nobles, H. (1999). What is "Atmosphere"? Hotels Online, Available: http://www.hotel-online.com/ News/PressReleases1999_4th/Nov99_NoblesAtmosphere.html.

Ransley, J. \& Ingram, H. (2001). What is "good" hotel design? Facilities. 19(1-2), 79-86.

Rutes, W.A., Penner, R.H. \& Adams, L. (2001). Challenges in hotel design: Planning the guestroom floor. Cornell Hotel and Restaurant Administration Quarterly. 42(4), 77-88.

Siguaw, J.A. \& Enz, C.A. (1999). Best practices in hotel architecture. Cornell Hotel and Restaurant Administration Quarterly. 40(5), 44-49.

Steiner, J. (2005). The art of space management: Planning flexible workspaces for people. Journal of Facilities Management. 4(1), 6-22.

Stipanuk, D.M. (2006). Hospitality Facilities Management and Design, 3rd edn, Educational Institute of the American Hotel and Motel Association, Lansing, MI, USA.

Thapa, D. (2007). Hotel lobby design: Study of parameters and attraction, Unpublished Masters' thesis. Texas Tech University, USA.

West, A. \& Hughes, J. (1991). An evaluation of hotel design practice. The Service Industries Journal. 11(3), 362-380.

West, A. \& Purvis, E. (1992). Hotel design: The need to develop a strategic approach. International Journal of Contemporary Hospitality Management. 4(1), $15-22$. 
Withiam, G. (1989). Laurence Geller: Building excitement. Cornell Hotel and Restaurant Administration Quarterly. 30(1), 26-27.

Withiam, G. (1997). B\&Bs: Fundamentally like hotels. Cornell Hotel and Restaurant Administration Quarterly. 38(6), 13.

Zemke, D.M.V. \& Shoemaker, S. (2007). Scent across a crowded room: Exploring the effect of ambient scent on social interactions. Hospitality Management. 26(4), 927-940. 